\title{
MDA Program against lymphatic filariasis: Are we on the path to success? Experience from Uttara Kannada District, Karnataka
}

\section{Praveen Kulkarni, Ravi Kumar', Ravi Marinayakanakoppalu Rajegowda, Harshith Gowdra Channabasappa, Ashok N C}

Department of Community Medicine, JSS Medical College, Mysore, ${ }^{1}$ Regional Office for Health and FW, Government of India, Bangalore, Karnataka, India

Address for the Correspondence: Dr. Praveen Kulkarni, Department of Community Medicine, JSS Medical College, Mysore, Bangalore, Karnataka, India. E-mail: prakulfi@gmail.com

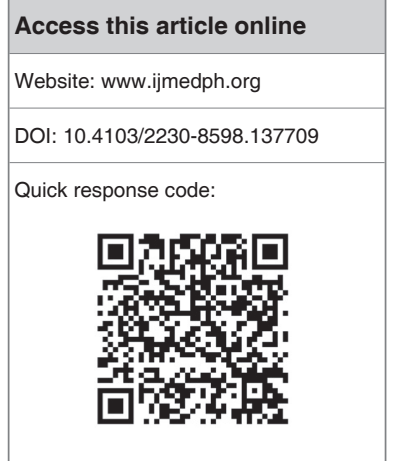

Context: Lymphatic filariasis or elephantiasis a serious public health problem in India. Millennium Development Goals and National Health Policies purport to eliminate filariasis by 2015 . The concept of mass drug administration (MDA) is to approach every individual in the target community and administer annual single dose of anti-filarial drugs (DEC or DEC + Albendazole). Aims: 1. Assess the coverage and compliance to MDA in the district. 2. Assess the awareness of elephantiasis among beneficiaries. 3. Assess the knowledge of drug distributors about filariasis and the MDA program. Materials and Methods: This cross-sectional study was conducted in one urban and three rural clusters in Uttara Kannada district of Karnataka for the period of one week. A total of 50 houses were selected in each cluster by systematic random sampling method and data were collected in a structured proforma by interview technique. Statistical Analysis Used: Descriptive statistics such as percentage, mean, and standard deviation. Results: Among 1,022 beneficiaries, the overall coverage of MDA was $82.3 \%$. Compliance among those who had received the tablets was $52.1 \%$. Effective coverage rate was $42.9 \%$. The compliance rate was significantly higher in rural areas [376 (58.6\%)] compared to urban areas [62 $(31.0 \%)]$. The most common reason quoted for not consuming drugs was "Don't want" $(50.4 \%)$. A total of $56 \%$ of the respondents were aware of the elephantiasis disease and MDA program. Conclusions: Even though there was high coverage of MDA in Uttara Kannada district, compliance and effective coverage rates were found to be poor.

Key words: Compliance, coverage, elephantiasis, lymphatic filariasis, MDA, Uttara Kannada

\section{INTRODUCTION}

Filariasis has been a major public health problem in India next only to malaria. The disease was recorded in India as early as the sixth century BC by the famous Indian physician Susruta in his book 'Susruta Samhita'. Although filariasis is not lethal, it causes debility and imposes severe social and economic burden on affected individuals, their families, and communities. ${ }^{[1,2]}$ Over 600 million people living in 250 districts across 20 states/Union Territories of India are endemic for the disease. Three-fourths of those at risk live in rural areas. An estimated 49 million individuals in India are infected with lymphatic filariasis. Of these, over 23 million people suffer from chronic forms of filariasis. Wuchereria bancrofti is the species that causes $99.4 \%$ of all cases of filariasis, while Brugia malayi is responsible for $0.6 \%$ of the problem. In Karnataka, 13.28 million people from 39 Talukas of 8 districts live in the endemic area; of these, 10.14 million are from rural areas.

National Health Policy (2002) has set the goal of elimination of lymphatic filariasis in India by 2015. Mass drug administration of a single dose of DEC was launched at the National Filaria Day (NFD) on June 5, 2004, by the Government of India. Co-administration of DEC with Albendazole, which was initiated in 2008, was expanded to all districts in 2009. ${ }^{[3]}$ A high coverage of more than $85 \%$ in endemic areas, which is sustained for five years, is required to achieve interruption of transmission and elimination of the disease in India. Even though the drug distribution in the country is more than $85 \%$, people who actually consume the drugs widely vary on the geographical and socio-cultural 
bases. The major challenge is drug delivery in urban areas and low priority given to lymphatic filariasis. ${ }^{[4]}$

With this background, following the instructions given by Regional office, Ministry of Health and Family Welfare, Government of India, this study was conducted in Uttara Kannada district, Karnataka, with the following objectives:

1. Assess the coverage and compliance to mass drug administration (MDA) in the district;

2. Assess awareness regarding elephantiasis among beneficiaries;

3. Assess the knowledge of drug distributors on the filariasis and MDA program.

\section{MATERIALS AND METHODS}

This cross-sectional study was conducted in Uttara Kannada, one of the coastal districts of Karnataka, India, during April 2013 for a period of one month. The line listing of lymphedema cases for the year 2012 was collected from the District Filaria Office and the Talukas were arranged in the ascending order of the incidence of lymphedema cases. One Taluka was selected for each low, medium, and high prevalence. One primary health center was selected by each Taluka and one subcenter from each PHC was selected randomly by lottery method. The same method was used for the selection of village from each of these subcenters for the household survey. As one ward was to be covered in urban areas, all wards in Kumuta — a town with the highest endemicity — were line listed from this area. One ward was selected randomly by lottery method for the household survey. Thus, one urban and three rural clusters were selected as per the instructions provided by the Regional Office, Ministry of Health and Family Welfare, Government of India. Data on the knowledge of drug distributors regarding filariasis was collected at the subcenter and the village level in a pre-tested structured proforma, which includes basic information a drug distributor should be having, for instance, whether they have ever heard of filariasis, the purpose of MDA program, and probable side effects of drugs used in MDA by interview technique. Same proforma was also used by authors for assessing the knowledge of drug distributors at Bidar district, Karnataka, in 2011..$^{[5]}$

House-to-house survey was conducted after a fortnight of drug distribution in the villages and wards selected by the abovementioned technique, for which the center of the village was identified by the help of a resident of the village; from this center, the four directions were identified and numbered. One direction was chosen randomly and a walkthrough survey was done to note the average number of houses in the street. Investigators randomly selected the first house on the road, and subsequently, every fifth house was selected by a systematic random sampling technique. A total of 50 houses were covered in each village and ward. Data regarding socio-demographic characteristics, coverage, and compliance to MDA and awareness regarding filariasis among beneficiaries were collected in a pre-tested structured proforma by interviewing the adult responsible respondent aged 18-60 years; the information was gathered after explaining the purpose of the survey and showing a flashcard containing an image of elephantiasis case, DEC, and albendazole tablets. The interview was conducted by one Assistant Professor and two second-year postgraduate students of Community Medicine who had received a one-day training on MDA program evaluation in the Regional Office of Health and Family Welfare, Government of India, Bangalore.

\section{Statistical analysis}

Data collected were entered in Microsoft excel-2010 and analyzed using SPSS version 18. Descriptive statistical measures such as percentage, mean, and standard deviation were applied. Inferential statistical test such as Chi-square test was applied for assessing the association of coverage, compliance, and effective coverage rate with locality. Associations were interpreted to be statistically significant at $P<0.05$.

\section{RESULTS}

\section{General characteristics}

Among 200 households comprising 1,022 beneficiaries (excluding children aged less than 2 years, pregnant women, and elderly suffering from chronic illnesses) surveyed, the majority [788 (77.1\%)] were in the age group of 15-60 years, while $507(49.6 \%)$ were male and $515(50.4 \%)$ female.

\section{Coverage and compliance of MDA}

Among 1,022 beneficiaries, DEC + Albendazole were distributed to $841(82.3 \%)$ individuals; of these, $413(49.1 \%)$ were male and $428(51.9 \%)$ were female. Thus, the coverage of MDA in Uttara Kannada district was $82.3 \%$. Among the beneficiaries who had received the tablets, $438(52.1 \%)$ consumed them (compliance rate). Effective coverage rate, which is the proportion of actual beneficiaries in the given community who had consumed the drugs, was 438 (42.8\%). The coverage of MDA was higher in the urban area $[200(84.0 \%)]$ compared to rural areas [641 (81.7\%)]. The compliance among those who had received the tablet was also higher in rural areas [376 (58.6\%)] compared to urban areas [62 (31.0\%)]; moreover, the difference was found to be statistically significant (Chi: $17.32, P=0.001)$. Effective coverage rate was significantly higher in rural areas $[376(47.9 \%)]$ compared to the urban areas [62 (26.0\%)] (Chi: 35.8, $P=0.001$ ) [Table 1]. The most common reason quoted for not consuming drugs was that they "Don't want" [203 (50.4\%)], followed by the fear of adverse drug reactions [99 (24.6\%)]. Among those who had consumed the tablets, only $35(8.0 \%)$ did that in front of the drug distributors. The most common reason quoted for not consuming the tablets in front of drug distributors was that they had not taken food at the time of distribution [199 (49.3\%)], followed by lack of information [99 $(24.6 \%)]$, and not present at home at the time of drug distribution [60 (14.8\%)]. Among those who consumed the tablets, only $12(2.7 \%)$ had developed adverse effects, among which fever was the most common [5 (41.7\%)] followed by 


\begin{tabular}{|c|c|c|c|c|c|}
\hline Setting & Yes & No & Total & $x^{2}$ value & $P$ \\
\hline \multicolumn{6}{|c|}{ Coverage* $^{*}$} \\
\hline Rural & $641(81.7)$ & $143(18.3)$ & $784(76.7)$ & 0.647 & 0.421 \\
\hline Urban & $200(84.0)$ & $38(16.0)$ & $238(23.3)$ & & \\
\hline Total & $841(82.3)$ & $181(17.7)$ & $1022(100.0)$ & & \\
\hline \multicolumn{6}{|c|}{ Compliance $^{* *}$} \\
\hline Rural & $376(58.6)$ & $265(41.4)$ & $641(76.2)$ & 17.32 & 0.001 \\
\hline Urban & $62(31.0)$ & $138(69.0)$ & $200(23.8)$ & & \\
\hline Total & $438(52.1)$ & $403(47.9)$ & $841(100.0)$ & & \\
\hline \multicolumn{6}{|c|}{ Effective coverage rate ${ }^{* * *}$} \\
\hline Rural & $376(47.9)$ & $408(52.1)$ & $784(76.7)$ & 35.8 & 0.001 \\
\hline Urban & $62(26.0)$ & $176(74.0)$ & $238(23.3)$ & & \\
\hline Total & $438(42.8)$ & $584(51.2)$ & $1,022(100.0)$ & & \\
\hline
\end{tabular}

Note: Figures in parentheses indicate percentages, ${ }^{*}$ Coverage: Number of beneficiaries who received drug/Total no. beneficiaries $\mathrm{X} 100, * * C o m p l i a n c e:$ Number of beneficiaries who consumed drug/No. beneficiaries who received drug $X 100, * * *$ Effective coverage rate: Number of beneficiaries who consumed drug/Total no. beneficiaries $X 100^{2}$

fatigue $[3(25.0 \%)]$. These adverse effects occurred on the day of drug intake and subsided without any medications within 24 hours. The most preferred method for the dissemination of information related to MDA for the future rounds of the program as mentioned by the respondents was television [101 (50.5\%)] followed by radio [25 (12.5\%)].

\section{Awareness of filariasis and MDA among beneficiaries}

Among 200 adult responsible respondents interviewed, majority of the respondents $[112(56 \%)]$ were aware of a disease called filariasis, and $64(32.0 \%)$ had seen a case of elephantiasis in their vicinity. A total of $112(56.0 \%)$ respondents knew the reason for MDA, but only $45(22.5 \%)$ of the respondents had prior information regarding the day and time of the MDA program of the year 2013. The most common source of information was Anganwadi/ASHA workers [26 (57.2\%)] in rural areas and announcement on loudspeaker (miking) $[22(44.0 \%)]$ in urban areas.

\section{Awareness of filariasis and MDA among drug distributors}

Among 21 drug distributors surveyed from 4 clusters, 16 (76.2\%) were aware of filariasis and $8(38.1 \%)$ had seen a case of lymphatic filariasis in their vicinity. A total of $14(66.7 \%)$ drug distributors were aware of the purpose and rationale of the MDA program, $16(76.2 \%)$ were aware of proper dosage of MDA, and $12(57.1 \%)$ were aware of the possible adverse effects of MDA.

\section{DISCUSSION}

Mass drug administration against lymphatic filariasis is an ambitious program by the government toward eliminating this chronic scourge from the country by 2015 . The present study was conducted in one of the coastal districts of Karnataka, which is endemic for the disease. The coverage of MDA observed in the present study was satisfactory $(82.3 \%)$. The sustained high level of coverage $(85 \%)$ for a minimum of five years is essential to achieve the interruption of transmission and elimination of the disease. ${ }^{[3,4]}$ The coverage observed in the present study was similar to the results of the study conducted by B. G. Ranganath in Gulbarga district of Karnataka (85\%), ${ }^{[6]}$ Ashwini Kumar in a neighboring Udupi district (73.4\%), ${ }^{[7]}$ Pradeep Kumar et al. in Gujarat state $(85.2 \%),{ }^{[4]}$ and T. Mahalakshmy at Puducherry $(76.2 \%) .{ }^{[8]}$ In contrast, Dr. D. M. Koradhanyamath in Bidar district of Karnataka observed the coverage to be $62.3 \%$. The compliance of MDA is a more sensitive indicator than the coverage because this indicates the actual consumption of tablets by the beneficiaries. In the present study, the compliance among those who had received the tablets was $52.1 \%$; this was similar to the observations made by B. G. Ranganath in Gulburga, ${ }^{[6]}$ where the compliance was $32.7 \%$ and Dr. D. M. Koradhanyamath ${ }^{[5]}$ in Bidar district $(60.4 \%)$. On the other hand, the compliance was as high as $85.6 \%$ in an independent external evaluation of MDA in Udupi district. ${ }^{[9]}$ Similar observations were made by Pradeep Kumar ${ }^{[4]}$ in Gujarat state and by T. Mahalakshmy at Puducherry, ${ }^{[8]}$ where compliance was $89 \%$ and $88.7 \%$, respectively. It is clear from the above results that even though the coverage in Uttara Kannada district was high, compliance was below standard. Effective coverage rate, which tests the actual drug intake against the total number of beneficiaries, was also as low as $42.8 \%$ in contrast to the observations made by Pradeep Kumar et al at Gujarat $(75.8 \%) .{ }^{[4]}$ These findings can be attributed to the fact that there is no seriousness about the disease as well as the strategy among beneficiaries. It is evident from the fact that the majority of the beneficiaries who did not consume the tablets quoted the reasons for non-consumption as "don't want to consume", "fear of adverse drug reactions", and "doubtful benefit on consumption," all of which are pure misconceptions. One of the best strategies for improving compliance, which has failed in the present district, is consumption of tablets in front of the drug distributors. Many beneficiaries attributed this to the most avoidable reasons such as not have consumed food at the time of drug distribution and not being present at home when the drugs were distributed, which showed the lack of information among the people regarding the days and timings of drug distribution. 
This can be effectively addressed by proper advocacy and behavior change communication BCC activities.

In the present study, there was significantly higher coverage and compliance to MDA in rural areas compared to the urban areas; this can be attributed to the fact that local primary care workers such as ASHAs and Anganwadi workers played a major role in community sensitization in rural areas, and such efforts were lacking in the urban areas. Furthermore, there was low awareness about the day of drug distribution (45\% in rural areas Vs $10 \%$ in urban areas), and many of the beneficiaries had not consumed tablets in front of drug distributors in urban areas $(25 \%$ in rural areas Vs $10 \%$ in urban area). Similar observations were made by Pradeep Kumar in Gujarat state, ${ }^{[4]}$ B. G. Ranganath in Gulburga district, ${ }^{[6]}$ and Dr. D. M. Koradhanyamath in Bidar district. ${ }^{[5]}$

In the present study, the awareness regarding filariasis among the beneficiaries was $66.7 \%$. This is similar to the observations made by A. K. Mukhopadhyay ${ }^{[10]}$ in Andhra Pradesh (65\%) and Dr. D. M. Koradhanyamath ${ }^{[5]}$ in Bidar district $(75 \%)$, and is in contrast to the observations made by Dorle $\mathrm{AS}^{[1]}$ in northern Talukas of Karnataka where only $31 \%$ of the respondents were aware of the disease. The reason for the high level of awareness in the present study could be the endemicity and the visible disfiguration and deformities caused by the disease.

\section{CONCLUSION}

Coverage of MDA in Uttara Kannada district was $82.3 \%$. Compliance among those who had received the tablets was $52.1 \%$. Effective coverage rate was $42.9 \%$. Coverage, compliance rate, and effective coverage rate were higher in rural areas compared to urban area. Only $35(8.0 \%)$ individuals had consumed tablets in front of drug distributors and $45(22.5 \%)$ had prior information regarding the day and time of the MDA program.

\section{RECOMMENDATIONS}

Low compliance of MDA can be addressed by effective BCC activities, behavior change communication, interpersonal communication. Better compliance in rural areas compared to urban areas itself gives us a clue regarding the involvement of local health personnel in mobilizing the community; this can be further strengthened and the same model applied in urban areas as well. The drug distributors should insist on the beneficiaries for 'on the spot' consumption of tablets.

\section{REFERENCES}

1. NVBDCP, National Vector Borne Disease Control Programme (NVBDCP). Annual Report: Ministry of Health and Family Welfare: 2009.

2. Guidelines for Mass Drug Administration. Available from: http://nvbdcp. gov.in/MDA.html [Last cited on 2013 Apr 02].

3. Government of India. Operational guidelines on elimination of lymphatic filariasis. Directorate NVBDCP, 22. Shamnath Marg, Delhi 110054, India; 2005.

4. Kumar P, Prajapati P, Saxena D, Kavishwar AB, Kurian G. An Evaluation of Coverage and Compliance of Mass Drug Administration 2006 for Elimination of Lymphatic Filariasis in Endemic Areas of Gujarat. Indian J Community Med 2008;33:38-42.

5. KoradhanyamathDharukaswami Mallayya, Kulkarni P, Holla R. Coverage and compliance MDA programme for lymphatic filariasis in Bidar district, Karnataka, India. Asian Pac J Trop Dis 2012;2:290-2.

6. Ranganath BG. Coverage survey for assessing mass drug administration against lymphatic filariasis in Gulbarga district, Karnataka, India. J Vector Borne Dis 2010;47:61-4.

7. Kumar A, Kumar P, Nagaraj K, Nayak D, Ashok L, Ashok K. A study on coverage and compliance of mass drug administration programme for elimination of filariasis in Udupi district, Karnataka, India. J Vector Borne Dis 2009;46:237-40.

8. Mahalakshmy T, Kalaiselvan G, Parmar J, Dongre A. Coverage and compliance to diethylcarbamazine in relation to Filaria Prevention Assistants in rural Puducherry, India. J Vector Borne Dis June 2010;47:113-5.

9. Kumar A, Kumar P, Nagaraj K, Nayak D, Ashok L, Ashok K. A study on coverage and compliance of mass drug administration programme for elimination of filariasis in Udupi district, Karnataka, India. J Vector Borne Dis 2009;46:237-40.

10. Mukhopadhyay AK, Patnaik SK, Satya Babu P, Rao KN. Knowledge on lymphatic filariasis and mass drug administration (MDA) programme in filaria endemic districts of Andhra Pradesh, India. J Vector Borne Dis 2008;45:73-5.

11. Dorle AS, Basavaraj M, Hiremath LD, Ghattargi CH, Umesh R, Manjula R, et al. The knowledge and perception about lymphatic filariasis in one of the endemic Talukas of Rural North Karnataka. J Clin Diagnc Res 2011;5:101-3.

How to cite this article: Kulkarni P, Kumar R, Rajegowda RM, Channabasappa HG, Ashok NC. MDA Program against lymphatic filariasis: Are we on the path to success? Experience from Uttara Kannada District, Karnataka. Int J Med Public Health 2014;4:243-6.

Source of Support: Nil, Conflict of Interest: None declared. 